\title{
Models for estimating capillary rise in a heavy clay soil with a saline shallow water table
}

\author{
S. A. Prathapar ${ }^{1}$, C. W. Robbins ${ }^{2}$, W. S. Meyer ${ }^{1}$, and N. S. Jayawardane ${ }^{1}$ \\ 1 CSIRO Division of Water Resources, Griffith Laboratory, Griffith, NSW 2680, Australia \\ ${ }^{2}$ USDA-ARS, Soil and Water Management Research Unit, Kimberly, ID 83341, USA
}

Received May 22, 1991

Summary. Shallow saline water tables underlie large areas of the clay soils in the Murray basin of Australia. Accurate estimation of capillary rise is important in formulating management strategies to avoid degradation of such soils. Measured capillary rise from a saline water table was compared with capillary rise estimated by three mathematical models of varying complexity and input requirement. A quasi steady state analytical model (QSSAM), a transient state analytical model (TSAM) and a numerical model (NM) were used. An undisturbed heavy clay soil core of $0.75 \mathrm{~m}$ diameter and $1.4 \mathrm{~m}$ deep was subjected to a static saline water table at $1.2 \mathrm{~m}$ from the surface. A wheat crop was grown on the core and the weekly capillary rise from the water table was measured. The electrical conductivity of a $1: 2$ soil : water extract was determined at $0.15 \mathrm{~m}$ depth intervals before and 21 weeks after the introduction of the saline water table. The QSSAM did not satisfactorily estimate the initial wetting of the subsoil and the estimated capillary rise was considerably lower than the measured values. Capillary rise estimated by the TSAM was reasonably close to the measured values, but the weekly rates fluctuated considerably. The NM estimated capillary rise quite satisfactorily throughout the experiment. Except near the soil surface, the electrical conductivity values estimated by the NM were close to the measured values. For estimating total capillary rise over large areas, the TSAM is preferred over the NM because of its fewer input requirements and shorter execution time.

Salinisation of soil, the increase in soluble salts in the root zone, is influenced by climate, soil type, crop, irrigation water quality and management practices, and the depth to, and salinity of the water table. The ability to estimate the rate of salinisation is vital for the management of irrigated areas in the Murray basin of Australia, where salinisation of heavy clay soils is primarily caused by capillary rise from saline shallow water tables.

Offprint requests to: S. A. Prathapar
A description of water transport in the unsaturated zone of a non-hysteretic, non-swelling soil is given by Richards (1931). Analytical models to estimate capillary rise from a water table could be formulated either with a steady state solution or with a transient solution for Richards' equation. Subsequently, the rate of salinisation could be estimated by combining an appropriate analytical solution for diffusive and convective solute transport with the capillary rise calculation, or by multiplying the rate of capillary rise by the concentration of salt in the water table. Numerical models to estimate capillary rise and salinisation in an unsaturated soil profile solve Richards' equation and the diffusive and convective solute transport equation simultaneously.

Analytical models to estimate capillary rise are efficient and easy to use when input data are sparse and uncertain. However, the analytical models are limited to certain idealised situations such as homogeneous and isotropic conditions. Numerical models, on the other hand, can accommodate spatial and temporal variation of soil properties and plant growth. The application of numerical models to complex conditions is generally restricted by the limited availability of temporal and spatial data.

The objective of this study was to compare the performance of a quasi steady state analytical model (QSSAM), a transient state analytical model (TSAM) and a numerical model (NM) for estimating capillary rise of a soil profile with a saline water table. Capillary rise and the increase in salt within the soil profile were estimated by the models and compared with experimental data.

\section{Formulation of models and application}

A QSSAM, a TSAM and a NM to solve Richard's equation were formulated and compared for their ability to estimate capillary rise on Mundiwa clay loam. Capillary rise in this study is defined as the volume of water leaving a static water table due to soil and plant evaporation. Soil physical properties used in the models were either mea- 
sured from unpublished data (J. Loveday, N. S. Jayawardane) for similar soils.

The quasi steady state analytical model (QSSAM)

In irrigated clay soils most of the roots are found within $0.75 \mathrm{~m}$ of the surface (Meyer and Barrs 1991). Thus the soil profile of $1.2 \mathrm{~m}$ was divided into a root zone of $0.75 \mathrm{~m}$ (DRZ) and a subsoil of $0.45 \mathrm{~m}$ (DSUB) in the QSSAM. Roots were assumed to be uniformly distributed within the root zone. Actual evapotranspiration (AET) on a particular day was determined by multiplying the pan evaporation by a corresponding crop coefficient $K_{c}$ for a wheat crop. Following Stapper et al., (1986) $K_{c}$ was set at 0.3 for the first 20 days after sowing (DAS); increased linearly to 0.8 at $60 \mathrm{DAS}$, kept constant at 0.8 until 150 DAS and decreased linearly to 0.3 at 180 DAS.

Initial total water content of the root zone (WRZ) and the subsoil (WSUB) were determined from the measured volumetric water content $(\theta)$ and depth of each zone. The WRZ on a particular day was calculated by subtracting AET and adding irrigation and rainfall (when applicable) to the previous day's WRZ. The resultant $\theta$ of the root zone $\left(\theta_{r z}\right)$ was determined by dividing the WRZ by DRZ. The change in WSUB ( $\triangle$ WSUB) was determined by estimating the area of the triangle indicated by the dashed lines in Fig. 1 as

$$
\Delta \text { WSUB }=0.5\left(\theta_{r 2,2}-\theta_{r z, 1}\right) \text { DSUB }
$$

where

$\theta_{r z, 2}$ : volumetric water content of root zone on a day

$\theta_{r z, 1}$ : volumetric water content of root zone on the previous day.

The resultant $\theta$ of the subsoil $\left(\theta_{\text {sub }}\right)$ was determined by dividing WSUB by DSUB. Capillary rise $J(L / T)$ from the water table to the root zone was estimated from a steady state solution for Richards' equation as,

$J=-K(\psi)\left(\frac{\mathrm{d} \psi}{\mathrm{d} z}+1\right)$

where,

$z \quad$ : vertical upward cartesian coordinate (L)

$K(\psi)$ : unsaturated hydraulic conductivity $(\mathrm{L} / \mathrm{T})$

$\psi \quad$ : matric potential (L)

$\theta \quad$ : volumetric water content $\left(\mathrm{L}^{3} / \mathrm{L}^{3}\right)$.

The $\psi_{r z}$ and the $K(\psi)_{\text {sub }}$ were determined using Campbell's (1974) functions

$\psi=\psi_{e}\left(\frac{\theta}{\theta_{s}}\right)^{\beta}$

$K(\psi)=K_{s}\left(\frac{\psi_{e}}{\psi}\right)^{2+\frac{3}{\beta}}$

$\psi_{e}$ : air entry value (L)

$\theta_{s}:$ saturated volumetric water content

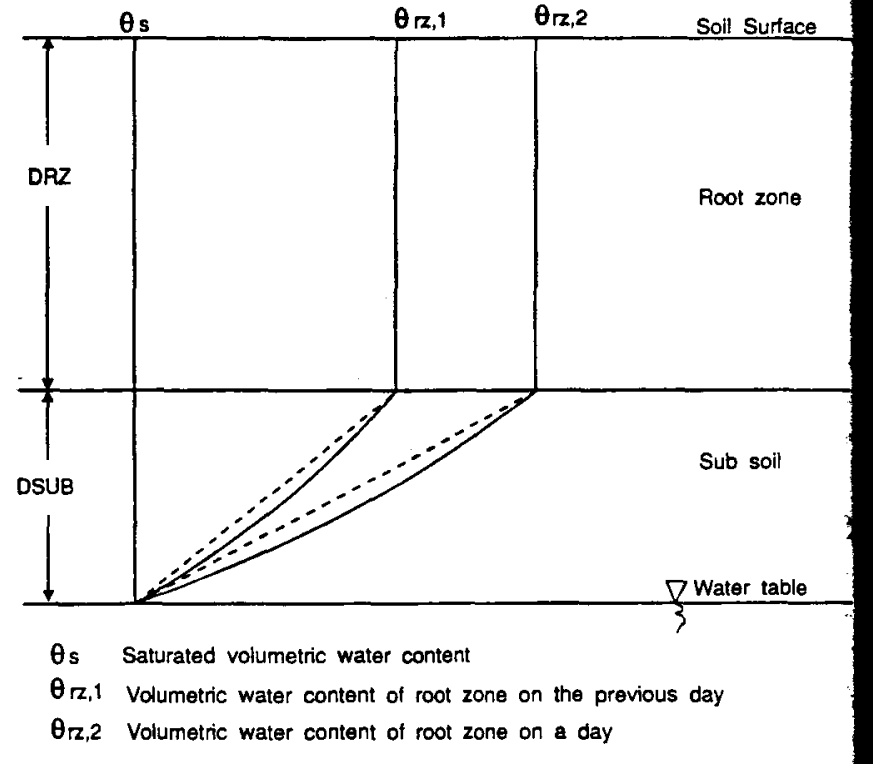

Fig. 1. Estimating the change in subsoil water content using a trian gular approximation

Table 1. Soil properties used in the QSSAM

\begin{tabular}{lc}
\hline Property & \multicolumn{1}{c}{ Value } \\
\hline Initial vol. water content of the soil profile & 0.29 \\
Saturated vol. water content of the profile $\theta_{s}$ & 0.40 \\
Air entry value of the soil profile in $\psi_{c}(\mathrm{~mm})$ & -39 \\
$\beta$ of the soil profile & -8.24 \\
Sat. hyd. conductivity of the soil profile $K_{s}(\mathrm{~mm} / \mathrm{d})$ & 2.0 \\
\hline
\end{tabular}

$\beta: \theta$ vs. $\psi$ decay parameter

$K_{s}$ : saturated hydraulic conductivity $(\mathrm{L} / \mathrm{T})$.

The values of soil properties used are given Table 1.

\section{The transient state analytical model (TSAM)}

Under transient state conditions, the matrix flux potentia $\Phi\left(\mathrm{L}^{2} / \mathrm{T}\right)$ (Gardner 1958; Raats and Gardner 1974) distri bution within a homogeneous soil profile with root. above the water table is given by an infinite time serie (Brandyk and Romanowicz 1989) as

$$
\begin{aligned}
\Phi(Z, T)= & Z \Phi_{0} / Z_{0}+A\left(Z-Z_{0}\right) \\
& +\sum_{n=1}^{\infty}\left[A_{n} \exp \left[-\left(1+\mu_{n}^{2}\right) T\right]+C_{n}\right] w_{n}(Z)
\end{aligned}
$$

$Z=\alpha Z / 2$

$T=\alpha^{2} t D / 4$

$Z_{0}=\alpha L / 2$

$A=\frac{\left(-\Phi_{0} / Z_{0}-2 q_{0} / \alpha\right)}{\left(1+2 Z_{0}\right)}$ 
$A_{n}=\frac{\left[-8 q_{0} \mu_{n} \sin \mu_{n} Z_{0}+16 \mu_{n} S\left(2 \sin \mu_{n} Z_{0}+\mu_{n} \exp \left(-Z_{0}\right)\right) / \alpha\left(1+\mu_{n}^{2}\right)\right]}{\left[\left(2 \mu_{n} Z_{0}-\sin 2 \mu_{n} Z_{0}\right) \alpha\left(1+\mu_{n}^{2}\right)\right]}$

$C_{n}=\frac{\left[16 \mu_{n}\left(q_{0}-\Phi_{0} \alpha-S_{x}\right)\left(2 \sin \mu_{n} Z_{0}+\mu_{n} \exp \left(-Z_{0}\right)\right)\right]}{\left(2 \mu_{n} Z_{0}-\sin 2 \mu_{n} Z_{0}\right)\left(1+2 Z_{0}\right)\left(1+\mu_{n}^{2}\right)^{2} \alpha}$

$w_{n}(Z)=\exp (Z) \sin \mu_{n}\left(Z_{0}-Z\right)$

$S_{x}=S /\left[\alpha\left(1+2 Z_{0}\right)\right]$

$\mu_{n}=-\tan \mu_{n} Z_{0}$

$K(\psi)=K_{s} \exp (\alpha \psi)$

$\Phi=\int_{-\infty}^{\psi} K(\psi) \mathrm{d} \psi=\frac{K(\psi)}{\alpha}$

$\Phi_{0}=\int_{-\infty}^{0} K(h) \mathrm{d} h=\frac{K_{s}}{\alpha}$

$\frac{\mathrm{d} K}{\mathrm{~d} \theta}=\alpha D$

$$
\begin{aligned}
& -\frac{\partial \Phi}{\partial z}-\alpha \Phi=q_{0}(t) \text { at } z=0 \\
& \Phi=\Phi_{0} \quad \text { at } z=\mathrm{L} \\
& \Phi=g(z)=-z \quad \text { at } t=0
\end{aligned}
$$

where

D : soil moisture diffusivity $\left(\mathrm{L}^{2} / \mathrm{T}\right)$

$K_{s} \quad$ : saturated hydraulic conductivity $(\mathrm{L} / \mathrm{T})$

$\alpha \quad: K(\psi)$ vs. $\psi$ decay parameter

$S \quad$ : root water uptake rate $(\mathrm{L} / \mathrm{T})$

$L \quad$ : depth to water table (L)

$t \quad$ : time (T)

$q_{0}(t)$ : surface evaporation at $t(\mathrm{~L} / \mathrm{T})$.

The TSAM was formulated using the same DRZ, DSUB, uniform root distribution, soil properties and crop coefficients as used in the QSSAM. The daily matric flux potential distribution above the water table was calculated using $\alpha=2.5$ in Eq. (5). Assuming that the root distribution function was not known, the water uptake term $S$ was set to zero. The daily surface boundary flux $q_{0}(t)$ was made equal to the AET calculated from pan evaporation and $K_{\mathrm{c}}$. Subsequently the daily capillary rise $J$ was calculated using

$J=\frac{\Phi_{0}-\Phi_{r z}}{L-\mathrm{DRZ}}-K_{\Phi_{r z}}$

where

$K_{\Phi_{r z}}$ unsaturated hydraulic conductivity at $\Phi_{r z}$.

\section{The numerical model (NM)}

LEACHM (Wagenet and Hutson 1989) was used as the NM in this study. This is a process-based numerical model of water and solute movement, plant uptake and chemical reactions in the unsaturated zone (LEACHM). This model uses a one dimensional finite difference solution for the transient unsaturated flow equation together with the transient diffusive and convective solute transport equation. Soil and crop evaporation are estimated from pan evaporation data and crop cover data. The model moves the salt as individual ions within the soil profile and then calculates the electrical conductivity (Robbins et al. 1980).

The soil profile was divided into 13 layers, each $0.1 \mathrm{~m}$ thick. The 13th layer represented the saline water table. Two simulations were made using the NM. The first simulation used a constant root profile and a maximum root length density of $15 \mathrm{~km} / \mathrm{m}^{3}$ to a depth of $0.75 \mathrm{~m}$. The second simulation used a growing root profile to a maximum depth of $0.75 \mathrm{~m}$. Both simulations assumed a density of 230 plants $/ \mathrm{m}^{2}$ and $100 \%$ crop cover at maturity (Meyer et al. 1990b). Chemical precipitation and cation exchange procedures were not used in the NM during these simulations since they were not available for the TSAM and the QSSAM.

Initial soil physical and chemical properties of layers used in the simulations are presented in Tables 2 and 3,

Table 2. Soil physical properties used in the NM

\begin{tabular}{|c|c|c|c|c|c|c|c|}
\hline \multirow[t]{2}{*}{$\begin{array}{l}\text { Layer } \\
\text { no. }\end{array}$} & \multirow[t]{2}{*}{$\begin{array}{l}\mathrm{EC} \\
\mathrm{d} \mathbf{S} / \mathrm{m}\end{array}$} & \multicolumn{2}{|c|}{$\begin{array}{l}\text { Soluble anions } \\
\mathrm{mmol} / \mathrm{l}\end{array}$} & \multicolumn{4}{|c|}{$\begin{array}{l}\text { Soluble cations } \\
\mathrm{mmol} / \mathrm{l}\end{array}$} \\
\hline & & $\mathrm{Cl}^{-}$ & $\mathrm{SO}_{4}^{-}$ & $\mathrm{Ca}^{++}$ & $\mathrm{Mg}^{++}$ & $\mathrm{Na}^{+}$ & $\mathbf{K}^{+}$ \\
\hline 1 & 1.3 & 1.9 & 0.4 & 1.1 & 0.9 & 1.9 & 0.2 \\
\hline 2 & 1.3 & 5.0 & 1.0 & 2.8 & 2.5 & 5.0 & 0.5 \\
\hline 3 & 1.5 & 6.9 & 1.4 & 3.9 & 3.4 & 6.9 & 0.7 \\
\hline 4 & 1.5 & 8.2 & 1.7 & 4.7 & 4.1 & 8.2 & 0.8 \\
\hline 5 & 1.5 & 10.0 & 2.0 & 5.6 & 5.0 & 10.0 & 1.0 \\
\hline 6 & 2.5 & 12.4 & 2.5 & 7.0 & 6.2 & 12.4 & 1.3 \\
\hline 7 & 3.0 & 18.6 & 3.0 & 8.4 & 7.5 & 18.6 & 1.5 \\
\hline 8 & 3.3 & 21.7 & 4.4 & 12.3 & 10.9 & 21.7 & 2.2 \\
\hline 9 & 3.9 & 26.4 & 5.3 & 14.9 & 13.2 & 26.4 & 2.7 \\
\hline 10 & 4.2 & 34.1 & 6.8 & 19.1 & 17.1 & 34.1 & 3.4 \\
\hline 11 & 5.3 & 37.2 & 7.4 & 21.0 & 18.7 & 37.2 & 3.7 \\
\hline 12 & 11.0 & 37.2 & 7.4 & 21.0 & 18.6 & 37.2 & 3.7 \\
\hline 13 & 15.5 & 70.0 & 11.2 & 31.1 & 27.0 & 57.0 & 5.4 \\
\hline
\end{tabular}

\begin{tabular}{lllll}
\hline Layer & $\psi_{e}(\mathrm{~mm})$ & $\theta_{i}$ & $\beta$ & $K_{\mathbf{0}}(\mathrm{mm} / \mathrm{d})$ \\
\hline 1 & 37 & 0.29 & -10.7 & 150 \\
2 & 37 & 0.29 & -13.0 & 100 \\
3 & 55 & 0.29 & -17.8 & 50 \\
4 & 60 & 0.29 & -18.5 & 2 \\
5 & 70 & 0.29 & -19.2 & 2 \\
6 & 70 & 0.29 & -20.1 & 2 \\
7 & 75 & 0.29 & -20.2 & 2 \\
8 & 85 & 0.29 & -20.3 & 2 \\
9 & 90 & 0.29 & -20.4 & 2 \\
10 & 96 & 0.29 & -20.5 & 2 \\
11 & 96 & 0.29 & -20.6 & 2 \\
12 & 96 & 0.29 & -20.6 & 2 \\
13 & 96 & 0.40 & -20.6 & 2 \\
\hline
\end{tabular}

Table 3. Initial soil chemical properties used in the NM 
Table 4. Input parameters for the models

\begin{tabular}{llll}
\hline Type of input & QSSAM & TSAM & NM \\
\hline Soil & $\begin{array}{l}\text { Profile } K_{s} \\
\text { Profile } \theta_{i} \\
\text { Profile } \theta_{s} \\
\text { Profile } \theta(\Psi) \text { function }\end{array}$ & $\begin{array}{l}\text { Profile } K_{s} \\
\text { Profile } \theta_{i} \\
\text { Profile } \theta_{s} \\
\text { Profile } K(\Psi) \text { function }\end{array}$ & $\begin{array}{l}\text { Layer } K_{s} \\
\text { Layer } \theta_{s} \\
\text { Layer } \theta(\Psi) \text { function } \\
\text { Permanent wilting point. Diffusion coefficient. } \\
\text { Dispersivity. }\end{array}$ \\
Plant & $\begin{array}{l}\text { DRZ } \\
K_{c}\end{array}$ & $\begin{array}{l}\text { DRZ } \\
K_{c}\end{array}$ & $\begin{array}{l}\text { DRZ } \\
\text { Max. (AET/PET). Root length density Min. root } \\
\text { water potential. Max root water potential. Root flow } \\
\text { resistance. Root profile distribution. Plant density. }\end{array}$ \\
Water & $\begin{array}{l}\text { Irrigation. } \\
\text { Pan evaporation }\end{array}$ & $\begin{array}{l}\text { Irrigation. } \\
\text { Pan evaporation }\end{array}$ & Irrigation. Pan evaporation. \\
Concentration & Concentration \\
of water table & $\begin{array}{l}\text { Two zones } \\
\text { daily time step }\end{array}$ & $\begin{array}{l}\text { Two zones } \\
\text { daily time step }\end{array}$ & Soluble anions and cations. \\
Model & & & 13 layers max. Permissible time step $0.05 \mathrm{~d}$. \\
\end{tabular}

respectively. Other properties used in the NM were: permanent wilting point $1500 \mathrm{kPa}$, dispersivity $40 \mathrm{~mm}^{2}$, molecular diffusion coefficient $120 \mathrm{~mm}^{2} / \mathrm{d}$, minimum root water potential $3000 \mathrm{kPa}$, maximum root water potential of $0 \mathrm{kPa}$, maximum ratio between AET and potential evapotranspiration (PET) 1.0, and root flow resistance $1.05 \mathrm{~d} / \mathrm{mm}$. A summary of all input parameters required by QSSAM, TSAM and NM are presented in Table 4.

\section{Estimation of salt increase}

The total increase in salt content within the profile during the growing season was estimated by multiplying the salt concentration in the water table by the cumulative capillary rise estimated by each of the models.

\section{Lysimeter experiment}

An undisturbed soil core, $0.75 \mathrm{~m}$ diameter and $1.4 \mathrm{~m}$ deep, of Mundiwa clay loam was installed in the lysimeter at CSIRO Division of Water Resources, Griffith (Meyer et al. 1985). Mundiwa clay loam is a duplex soil with approximately $0.2 \mathrm{~m}$ of clay loam overlying a heavy clay subsoil. A chloride dominant saline static water table (EC $15.5 \mathrm{dS} / \mathrm{m}$ ) was maintained at a depth of $1.2 \mathrm{~m}$ using a Mariotte tank. The rate of capillary rise was taken as the volume of water supplied by the Mariotte tank to maintain the water table at $1.2 \mathrm{~m}$. This volume was monitored weekly.

Wheat (var. Bindawarra) was sown on the core. Neutron probe readings were obtained regularly during the growing season to determine soil water content. Irrigation water of approximately $0.1 \mathrm{dS} / \mathrm{m}$ electrical conductivity was applied periodically to the soil surface to meet the soil water deficit. Weekly evaporation was monitored with a class A evaporation pan located at a meteorological station $80 \mathrm{~m}$ from the lysimeter. Meaured weekly capillary rise, pan evaporation and irrigation volumes are given in Table 5.

Soil samples were obtained down the profile at $0.15 \mathrm{~m}$ intervals, before the introduction of the saline water table and after 21 weeks. Electrical conductivity of a 1:2 soil: water suspension was determined from these samples.

Results and discussion

\section{Lysimeter measurements}

The rate of capillary rise was high during the first 4 weeks after introduction of the saline water table (Table 5). The initial volumetric water content $\theta_{i}$ of 0.29 , resulted in an optimal combination of $\psi_{\text {sub }}$ and $K(\psi)_{\text {sub }}$ which facilitated rapid wetting of the subsoil. The reduction in capillary rise during the first 11 weeks was due to a decrease in $\Delta \psi$ between the root zone and the water table. Irrigation water increased $\psi$ in the root zone, while $\psi$ in the subsoil was increased due to capillary rise from the saline water table.

Between the 5th and the 11th week capillary rise was approximately $1.4 \mathrm{~mm} /$ week. During this period pan evaporation increased from 12.8 to $22 \mathrm{~mm} /$ week and the soil water deficit was met by two irrigations, each of $35 \mathrm{~mm}$. Despite frequent irrigation, the rate of capillary rise increased to an average of $3.6 \mathrm{~mm} /$ week between the 11 th and 21st week. During this period 11 irrigations totalling $427 \mathrm{~mm}$ were applied. Pan evaporation increased from $22 \mathrm{~mm} /$ week to $49 \mathrm{~mm} /$ week. Capillary rise values measured were consistent with the observations made by Meyer et al. $(1990 \mathrm{a})$. They measured daily capillary rise from a shallow water table in Mundiwa clay 
Table 5. Capillary rise, pan evaporation and irrigation ( $\mathrm{mm} /$ week)

\begin{tabular}{|c|c|c|c|c|c|c|c|}
\hline \multirow[t]{2}{*}{ Week no. } & \multirow{2}{*}{$\begin{array}{l}\text { Pan eva- } \\
\text { poration }\end{array}$} & \multirow{2}{*}{$\begin{array}{l}\text { Irriga- } \\
\text { tion }\end{array}$} & \multirow{2}{*}{$\begin{array}{l}\text { Measured } \\
\text { capillary } \\
\text { rise }\end{array}$} & \multicolumn{4}{|c|}{ Estimated capillary rise } \\
\hline & & & & QSSAM & TSAM & $\begin{array}{l}\text { NM } \\
\text { Uniform } \\
\text { roots }\end{array}$ & $\begin{array}{l}\text { NM } \\
\text { Growing } \\
\text { roots }\end{array}$ \\
\hline 1 & 10.8 & & 24.0 & 0.1 & 4.5 & 18.5 & 18.5 \\
\hline 2 & 9.8 & & 12.8 & 0.1 & 3.5 & 8.4 & 8.4 \\
\hline 3 & 10.0 & & 6.7 & 0.1 & 4.6 & 5.5 & 5.5 \\
\hline 4 & 16.8 & 20 & 4.0 & 0.2 & 3.1 & 4.2 & 4.2 \\
\hline 5 & 12.8 & & 2.1 & 0.1 & 2.8 & 3.4 & 3.4 \\
\hline 6 & 13.2 & & 1.7 & 0.2 & 3.5 & 3.1 & 3.1 \\
\hline 7 & 11.6 & & 1.3 & 0.3 & 5.3 & 2.9 & 3.1 \\
\hline 8 & 15.2 & & 1.2 & 0.4 & 4.2 & 3.0 & 3.2 \\
\hline 9 & 19.4 & 35 & 1.2 & 0.5 & 3.4 & 3.0 & 3.2 \\
\hline 10 & 18.5 & 35 & 1.0 & 0.5 & 2.0 & 2.7 & 2.9 \\
\hline 11 & 22.0 & & 1.0 & 0.5 & 6.7 & 2.5 & 2.7 \\
\hline 12 & 42.5 & 60 & 1.3 & 0.4 & 2.0 & 2.4 & 2.6 \\
\hline 13 & 39.5 & 20 & 2.5 & 0.6 & 5.9 & 2.3 & 2.5 \\
\hline 14 & 41.9 & 25 & 2.5 & 0.8 & 0.4 & 2.4 & 2.6 \\
\hline 15 & 40.6 & 25 & 3.6 & 1.6 & 5.3 & 2.7 & 2.9 \\
\hline 16 & 33.7 & & 4.0 & 5.5 & 7.4 & 2.7 & 2.9 \\
\hline 17 & 59.8 & 85 & 6.2 & 3.6 & 0.4 & 3.1 & 3.1 \\
\hline 18 & 42.7 & 45 & 4.0 & 1.1 & 1.5 & 2.8 & 2.8 \\
\hline 19 & 56.8 & 45 & 4.3 & 0.9 & 3.1 & 2.5 & 2.5 \\
\hline 20 & 58.0 & 51 & 5.1 & 0.8 & 3.4 & 2.5 & 2.5 \\
\hline 21 & 49.0 & 71 & 2.8 & 0.5 & 0.6 & 2.5 & 2.5 \\
\hline 22 & 54.2 & & 1.8 & 0.5 & 3.9 & 2.4 & 2.4 \\
\hline 23 & 35.0 & & 1.7 & 0.7 & 3.8 & 2.4 & 2.4 \\
\hline 24 & 62.0 & & 1.0 & 1.9 & 6.7 & 2.4 & 2.4 \\
\hline 25 & 70.2 & & 1.4 & 4.9 & 6.0 & 2.1 & 2.1 \\
\hline
\end{tabular}

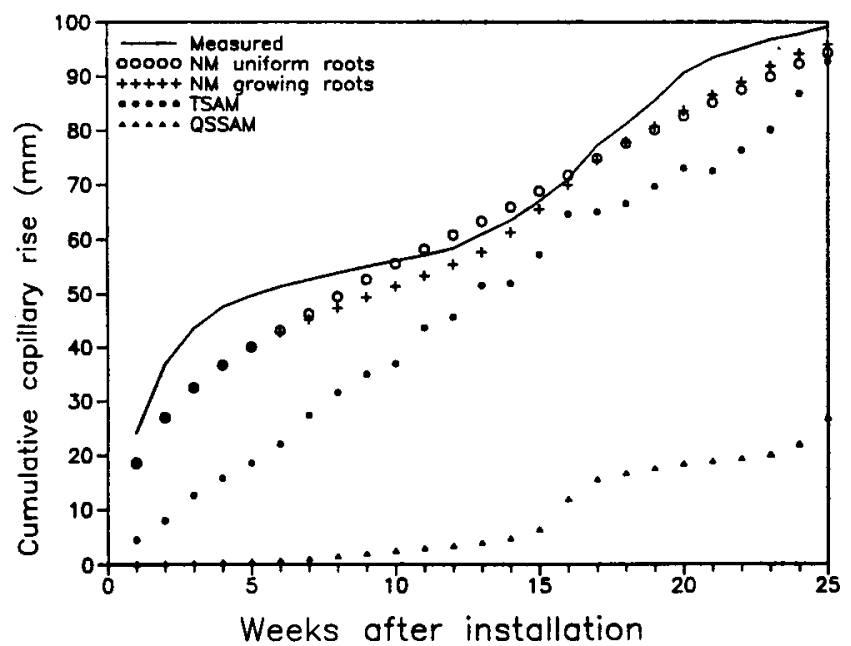

Fig. 2. Measured and estimated cumulative capillary rise

loam in a weighing lysimeter and found that, except on the day of irrigation, a measurable capillary rise occurred every day and increased with time after irrigation.

Capillary rise decreased to an average of $1.5 \mathrm{~mm} /$ week between the 22 nd and the 25 th week. Irrigation water was not applied during this period. During this time the wheat crop reached physiological maturity and root water uptake decreased.

\section{Simulation of capillary rise}

Measured and estimated weekly capillary rise for a period of 25 weeks after installation of the water table are presented in Table 5. Measured and estimated cumulative capillary rise values are presented in Fig. 2.

The QSSAM under-estimated the initial wetting of the subsoil because calculated $K(\psi)_{\text {sub }}$ and $\psi_{r z}$ were too low to result in capillary rise until the end of the 7th week. Although the capillary rise estimated by the QSSAM followed the trend of measured capillary rise after the 9th week, the estimated values were consistently lower than the measured values.

The TSAM also under-estimated intial wetting of the subsoil during the first three weeks. However, the weekly capillary rise estimated by TSAM during this period was closer to the measured values than the capillary rise estimated by the QSSAM. Between the 6th and the 16th weeks the capillary rise values estimated by the TSAM were higher than the measured capillary rise values. Between weeks 17 and 25, the capillary rise values estimated by the TSAM were lower than the measured capillary rise. This is probably due to the use of constant root depth in the TSAM. It is postulated that the effective root depth was less than $0.75 \mathrm{~m}$ during the first 16 weeks, which resulted in higher estimated capillary rise values than the measured values. Further root growth may have occurred below $0.75 \mathrm{~m}$ after the 16 th week, resulting in lower estimated capillary rise compared with the measured values. 


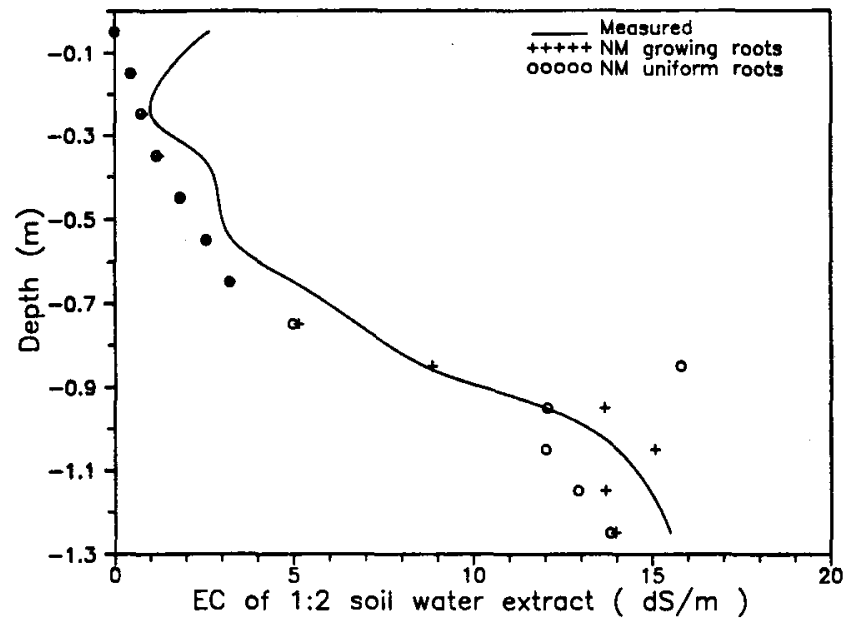

Fig. 3. Measured and estimated Electrical Conductivity profile after 21 weeks

Capillary rise values estimated by the TSAM were very sensitive to changes in $\theta$. Estimates decreased rapidly following an irrigation and increased rapidly as the soil began to dry. This caused estimated capillary rise to fluctuate rapidly than measured values.

The NM estimated the initial wetting of the soil profile much better than either the QSSAM or TSAM (Table 5). Figure 2 shows that cumulative capillary rise values estimated using a growing root distribution were closer to the measured values than those using a uniform root distribution. However, the differences between the two simulations were negligible.

Figure 3 compares the measured EC values 21 weeks after introducing the saline water table with $\mathrm{EC}$ values estimated by the NM. Both NM simulations results in a similar EC distribution within the profile and closely followed the pattern of the measured EC values except in the surface soil layers. This discrepancy indicates that the NM did not satisfactorily estimate the deposition of salt near the surface and subsequent downwards diffusion of salt. Other discrepancies were slightly smaller in the simulation made with growing root distribution than the simulation made with an uniform root distribution.

Total salt increase estimated in the root zone by the NM was very close to the measured value while that estimated by the TSAM was slightly lower. The QSSAM estimate was far too low. The salt increase estimated from measured capillary rise was $27.4 \mathrm{t} / \mathrm{ha}$. The QSSAM, the TSAM, the NM simulation assuming uniform roots and the NM simulation growing roots estimated 7.9, 25.4, 26.0 and $26.7 \mathrm{t} / \mathrm{ha}$ salt increase respectively. The lower rate of salinisation estimated by the QSSAM was primarily due to its inability to estimate the initial wetting of the subsoil satisfactorily.

The data required for the NM were more detailed than for the analytical models (Table 4). When executed on an AT286 personal computer with a 80287 maths co-processor, the QSSAM, TSAM and NM took $7 \mathrm{~s}, 9 \mathrm{~s}$ and $3723 \mathrm{~s}$ respectively, to estimate capillary rise and salinisation during 177 days. The high CPU requirement of the NM was primarily due to the discretisation of the soil profile into 13 layers, the maximum permissible time step and the maximum permissible change in water content in a laye during a time step.

\section{Conclusions}

The performance of the NM was excellent. Capillary rise estimated by the NM assuming growing roots was marginally better than that estimated assuming a uniform root profile. Except near the soil surface, the electrical conductivity profile estimated by the NM was similar to the measured electrical conductivity profile.

Cumulative capillary rise estimated by the TSAM was within $7 \%$ of the measured capillary rise although the weekly values had a wide variability around the measured ones. The capillary rise estimated by the TSAM generally followed the trend observed in the soil core. The TSAM also responded to irrigation and soil water status better than the QSSAM. The QSSAM did not estimate the capillary rise satisfactorily.

Although the NM estimated the capillary rise and salinisation satisfactorily, the data and computing requirement of the NM was considerably higher than that of the analytical models. Hence, the application of the NM to larger irrigation areas with varying soil types, depth to water table and agronomic practices may not be feasible. Under such circumstances, the TSAM may be suitable for estimating capillary rise from the water table where net long term effects are needed. The steady state model is not recommended when the soil water balance is frequently altered by irrigation.

Acknowledgements. The experiment described in this study was conducted in collaboration with H. A. Percy and A. van der Lelij of the Department of Water Resources, Griffith, NSW 2680. We thank them for allowing us to use the data. Dr. E. Humphreys is thanked for reviewing the manuscript.

\section{References}

Brandyk T, Romanowicz R (1989) Some aspects of soil moisture control for soils with shallow groundwater levels. In Proc "Symposium Groundwater Management: Quantity and Quality". IAHS Publ 188: 19-28

Campbell G (1974) A simple method for determining unsaturated hydraulic conductivity from moisture retention data. Soil Sci 117:311-314

Gardner, WR (1958) Some steady state solutions of the unsaturated moisture flow equation with application to evaporation from a water table. Soil Sci 85:228-232

Meyer WS, Barrs HD, Smith RCG, White NS, Heritage AD, Short DC (1985) Effect of irrigation on soil oxygen status and root and shoot growth of wheat in a clay soil. Aust J Exp Agric Anim Husb 25: 636-641

Meyer WS, Prathapar SA, Barrs HD (1990a) Water flux to and from shallow water tables on two irrigated soils. Proceedings of the symposium on "Management of soil salinity in South East Australia". Australian Society of Soil Science Inc, Riverina Branch, p 79-88

Meyer WS, Tan CS, Barrs HD, Smith RCG (1990 b) Root growth and water uptake by wheat during drying of undisturbed and repacked soil in drainage lysimeters. Aust J Agric Res 41: 253-265 
Meyer WS, Barrs HD (1991) Roots in irrigated clay soils: Measurement techniques and response to rootzone conditions. Irrig Sci 12:125-134

Raats PAC, Gardner WR (1974) Movement of water in the unsaturated zone near a water table. In van Schilfgaarde $J$ (ed) Drainage for agriculture. Agronomy NO 17. American Society of Agronomy, Madison USA, pp 311-357

Richards LA (1931) Capillary of liquids through porous mediums. Physics 1:318-333

Robbins CW, Wagenet RJ, Jurinak JJ (1980) A combined salt transport-chemical equilibrium model for calcareous and gypsiferous soils. Soil Sci Soc Am J 44:1191-1194
Stapper M, Keegan GM, Smith RCG (1986) SIRAGCROP computer based crop management: irrigation scheduling service. Proc Irrigation 86. Darling Downs Soil and Water Studies Centre and Irrigation Association of Australia, pp 137-153

Wagenet RJ, Hutson JL (1989) LEACHM: A process based model of water and solute movement, transformation, plant uptake and chemical reactions in the unsaturated zone. Centre of Environmental Research, Cornell University, Ithaca New York, USA 